\title{
The Flipped Classroom: A Mixed Methods Study of Academic Performance and Student Perception in EAP Writing Context
}

\author{
Renata Pavanelli \\ Broward College \\ Department of ESL \\ 4205 Bonaventure Blvd \\ Weston, FL 33332, USA
}

\begin{abstract}
The flipped classroom relies on the use of video technology to create instructional lectures delivered online and classroom meetings with in-class exercises that involve active learning. The main research method of this study consisted of a mixed methods embedded design with a quasi-experimental study. This study consisted of 22 participants enrolled in two advanced EAP writing courses in a large Southern State College and sought to measure whether the flipped model improved students' academic writing performance and understand their perceptions of the flipped instruction. Results indicated that there were statistically significant differences in students' academic learning outcomes between the control group and the treatment group. Qualitative results also indicated that students positively perceived the use of the flipped model as more effective and as a great resource of learning that helped them improve their writing skills in an interactive and collaborative environment.
\end{abstract}

Keywords: flipped classroom, flipped instruction, EAP, writing, academic performance, perceptions, active learning, motivation.

\section{Introduction}

Writing is a cognitively complex skill that is not naturally acquired. The process of writing in academic settings can be challenging and difficult. For EAP students to improve their writing skills, writing strategies and techniques along with language skills should be taken into consideration. Academic writing can be learned through interaction and practice of composing, formulating, and analyzing new ideas. Additionally, students should receive sufficient feedback about their errors and be able to revise and reflect on their own academic writing. For students to become proficient in writing, writing instruction must include writing practice, collaboration, and self-correction after receiving teachers' feedback. However, class time is limited when reviewing all the required language structures along with teaching the writing process. The flipped classroom is a model that can refine this situation. This model reverses the traditional teaching procedures and uses online instructional videos to deliver course content outside the classroom. These instructional videos give students the ability to take charge of their learning and control their learning style and pace of learning by pausing, rewinding, or fast-forwarding the lectures.

By watching these instructional videos prior to the class meeting, students come prepared and are able to participate in class activities that deepen their conceptual knowledge of the newly acquired content. By shifting the lecture out of the classroom, the use of in-class time is more effective and efficient as well as more active and engaging (Bergmann \& Sams, 2012; Hung, 2015; Little, 2015; Strayer, 2007; Tucker, 2012). The flipped model frees up class time for more meaningful in-class activities and creates more opportunity for one-on-one time with the instructor, which focuses on students' higher level cognitive processes (Little, 2015; Westermann, 2014).

By incorporating the flipped model in EAP writing courses, students review the language elements via online instructional videos outside the classroom and have more class time to practice key concepts of writing in collaborative and interactive ways. Students also work collaboratively with their instructor and peers so that they can improve their writing skills by receiving instant feedback on their writing. In addition, the flipped classroom promotes self-correction so students can recognize and correct their errors on their own. However, there are not many well-documented investigations in the literature that show whether this innovation improves the learning experience. Academic research into the effectiveness and student perceptions of the flipped model is limited at 
present. Thus, additional research is needed to investigate the impact of the flipped model in the academic field of English for Academic Purposes.

This study investigated the impact of the flipped classroom model to a traditional lecture instruction in two advanced EAP writing courses via a blended learning instructional format. Based on the information needs, the following research questions were formulated:

1.Do students in EAP writing courses improve their academic performance in the flipped classroom model?

2.What are students' perceptions about learning academic writing in a flipped classroom?

\section{Literature Review}

The face-to-face approach has been the standard method in higher education. However, online learning has grown significantly in the past decade. As DiRienzo and Lilly (2014) states, more students require flexibility in their schedules to meet both work and family obligations. With technology becoming more popular, educators have tried to find new learning strategies to increase the effectiveness of the learning process. However, using technology alone is not as effective as integrating it into teaching approaches. A new model of blended learning called the flipped classroom emerged. The definition of the flipped classroom model is fairly new and has been open to interpretation. It is routinely defined as a new pedagogical approach to blended learning that flips the traditional classroom pedagogy. In the flipped model, the delivery of content takes place outside the classroom, and what is traditionally done outside the classroom is instead done in class.

Strayer (2012) states that the flipped model "moves the lectures outside the classrooms and uses learning activities to move practice with concepts inside the classroom" (p. 171).Using a more broad definition of the flipped model, Bishop and Verleger (2013) define "the flipped classroom as an educational technique that consists of two parts: interactive group learning activities inside the classroom, and direct computer-based individual instruction outside the classroom" (p. 5). They also argue that "to meet the criterion of a flipped classroom, outof-class activities must include required video lectures; in-class activities must be required, and must involve interactive learning activities" (p. 10).Butt (2014) asserts that "the flipped classroom is moving the 'delivery' of material outside of formal class time (through the use of extensive notes, video recorded lectures and other appropriate means) and using formal class time for students to undertake collaborative activities relevant to the material" (p. 33). Moreover, he states that the flipped classroom model brings more active student engagement with the interactive activities inside the classroom, moving the more traditional activities outside of the classroom. Hung (2015) also claims that the principles supported by the flipped model are grounded in theoretical understanding of active learning. She argues that active learning instructional strategy encourages student engagement and improves student learning.

One of the benefits of the flipped model is that it is tangled with Bloom's taxonomy (2001). As opposed to traditional classroom instruction that requires lower levels of thinking skills, the flipped model provides students with an opportunity during class time "to develop higher order thinking under teacher guidance and with peer support" (Hung, 2015, p. 82).L2 writing courses are didactic and require a large amount of content on the low end of Bloom's taxonomy, so the flipped model has likely undergone a great transformation. By flipping the course, instructional videos are valuable sources for shifting the lower levels of Bloom's taxonomy outside the class, focusing on the upper end of the taxonomy during class time (Brame, 2013).

It is also important to note that the flipped model does not exclude teachers from the learning process; it simply restructures the contact time spent with students in the classroom. According to Little (2015), teachers have "a prominent role in helping learners apply taught content, ensuring this application is done correctly" (p. 267).Furthermore, teachers are crucial to maintain the pace of learning, and their content knowledge is essential to the success of students. Hamdan et al. (2013) argues that the flipped model allows teachers to "break the lecturecentered instructional model by shifting the focus from the curriculum pacing guide to students learning needs" (p. 3). The flipped model creates student-centered learning with practical instruction along with collaborative techniques. By assigning online instructional videos outside the classroom and more collaborative and interactive learning activities inside the classroom, students focus on interacting with their peers and working on solutions to problems with the guidance of their instructor.

Some studies based on whether students improve educational experiences and how they perceive the flipped model are reported next. Little (2015) completed a small-scale study in which he investigated whether the flipped classroom model elicited a positive change in student academic performance compared to a course taught via a 
traditional delivery method. In this case study, Little (2015) used a class of nine beginning-level Psychology students during a period of six months.

His study involved varied and active class sessions which were student-led and included collaborative learning that promoted creative thinking. When comparing the flipped model against a course taught via the traditional approach, Little (2015) stated that the flipped model presented positive results with higher percentages scores. In addition, feedback from participating students was largely positive in which participants responded that they would choose to study via a flipped model in the future.

Thompson and Mombourquette (2014) also compared two teaching methodologies, the flipped model and a traditional method in three introductory Business Administration classes. Two groupswere taught using the traditional lecture instruction and the third group was taught using the flipped model. They compared grade results and interviewed students to allow them to express their personal experiences about the flipped instruction. Results showed that there were no differences when comparing grades from the two traditional groups and the flipped group. However, results from the interview showed that student perceptions of flipped model were positive since they had more opportunities to interact with the peers and instructor in class.

Other studies focused mainly on the investigation of student perceptions of the flipped model. Strayer (2012), for example, conducted a study that compared the effects of the flipped model to a traditional lecture format in two college level introductory statistics courses. When comparing the responses from thetwo groups, he reported that students were not completely satisfied with the flipped instruction but indicated that they were open to collaborative learning and innovative teaching methods.

Butt (2014) also found positive responses in an actuarial science course in Australia. The research was based on reading passages read outside of class and more active activities moved to class time. The majority of the students stated that the flipped classroom model was more beneficial to their learning experience compared to face-to-face approach. However, students would like to have pre-recorded materials in addition to the course material. It takes us back to Bishop and Verleger (2013), who stated that the definition of flipped classroom means interactive activities inside the classroom and computer-based instruction outside the classroom. Thus, Butt's research can be considered irrelevant to the study of flipped classroom. Not all research on the flipped model in higher education has reported positive effects. Previous studies illustrated mixed findings in terms of the impact of the flipped model on student academic performance and student perceptions of the flipped classroom. There is littleempirical evidence of the efficacy of the flipped classroom as a model to improve student language learning.

Although Little (2015) showed positive student perceptions of the flipped model and improvements on academic performances, a limited sample size of nine was exposed to the flipped instruction, which could doubt the representativeness of these findings and be compromised by external validity.Butt (2014) also indicated that student perceptions of the flipped model were positive; however, his research is not relevant here given that he did not implement online instructional videos. Strayer (2012) showed some positive student perceptions of the flipped classroom model, but he did not analyze student performance between the control and experimental groups. Furthermore, Thompson and Mombourquette (2014) compared grade results, but there was no quantitative evidence that the grade results supported their claims other than students' opinions of the learning experience. In addition, most of the researches have been conducted in different fields other than in EAPacademic settings. For this reason, there is an urgent need for further research in this area to address the impact of the flipped classroom model in English for Academic Purposes settings.

\section{Methods}

The mixed methods design considers multiple viewpoints, perceptions, and standpoints., which is believed to generate insights into the research questions, resulting in enriched understanding of complex research problems. The best philosophical positions in mixed methods are post-positivism, associated with quantitative research, and constructivism, related to qualitative research. Many mixed methods writers have argued that the primary philosophical assumption to support mixed methods is pragmatism (Johnson \& Onwuegbuzie, 2004). They argue that "one or more of the pragmatisms can provide a philosophy that supports paradigm integration and helps mixed research to peacefully coexist with the philosophies of quantitative and qualitative research" (Johnson, Onwuegbuzie\& Turner, 2007). In order to identify potential best practices in EAP writing instruction, it was essential to collect both quantitative academic performance data and qualitative perception data from the 
participants involved. This study was conducted using both post-positivist and social constructivist worldviews using a mixed methods embedded design (Creswell \& Plano Clark, 2011).

The mixed methods embedded design consists of the collection and analysis of both quantitative and qualitative data with one form of data playing a supporting role. In this study, the qualitative data were embedded and played a secondary role within the experimental study. The primary purpose of using this design was to address different research questions requiring different data and to assess whether the flipped classroom had a significant effect on student academic performance. The purpose of including the qualitative data was to further understand experimental results and to explain reactions to participants in the experiment. The rationale for using a mixed methods embedded design was that the quantitative data and their analysis provided understanding of the research problem. The qualitative data and their analysis refined and explained the statistical results by exploring participants' views in depth.This was a quasi-experimental study with a mixed methods embedded design that investigated student academic performance and their perceptions of the flipped classroom model in two advanced EAP writing courses via a blended learning instructional format. The control group was a blended 8-week class and received the traditional lecture instruction during the fall 2015 term. The experimental group was a blended 12-week class and was taught using the flipped classroom model during the spring 2016 semester. Both classes were three-credit hour courses, the equivalent of 48 contact hours per semester.

\subsection{Data Collection}

This study combined quantitative and qualitative forms of analysis to gain insights into the EAP student academic performance and perceptions of a flipped classroom. Both the control group and the experimental group were conducted using a computer use questionnaire to collect information about students' frequency and ability to use computers and the internet as well as a pretest and a posttest to analyze student academic performance. In addition, the experimental group received a student perception questionnaire to collect student perceptions of the flipped instruction. The student perception questionnaire was anonymous and consisted of open and closed questions.

\subsubsection{Sampling}

The participants in this study consisted of 22 EAP students (women, $n=17$; men, $n=5$ ) who were enrolled in two advanced EAP writing courses during fall 2015 and spring 2016, from a large Southern State College. The participants were assigned into two groups. The control group consisted of 9 participants while the experimental group had a total of 13 participants.

\subsubsection{Procedure}

Both the control group and the experimental group contained the same course outline, including eight lessons (five lessons about language structure and three lessons about the writing process), writing assignments, and online quizzes after each lesson. The control group received the traditional lecturing format with the lessons taught inside the classroom and homework and assignments completed outside the classroom. The experimental group was taught using the flipped classroom model. Students watched narrated video lessons outside the class and completed their homework and assignments inside the class. The lessons were created by the instructor and contained the same course content for both groups; however, these lessons were narrated and saved in video format for the experimental group. This study was divided in three phases: preparation, instruction, and evaluation. In the preparation phase, students in both groups were pretested to assess their prior knowledge of the course content and surveyed using the computer use questionnaire to gather information on their ability to use computers and the internet. In the instruction phase, students in the control group were taught using traditional lecture inside the classroom and assigned homework and assignments to be done outside the classroom. At the beginning of each class, homework and assignments were reviewed, collected, and graded to ensure correctness and completeness. Then, the next lesson was covered. After each lesson, students took an online quiz designed to assess students' understanding of the learning material.

Contrary to the control group, students in the experimental group were taught using the flipped model via online video lessons outside the class. After watching the video lessons, students answered a set of questions and submitted their responses online via D2L course management system prior to the class meeting in order to ensure that they would come prepared for class. 
At the beginning of each class, the questions were reviewed and students were given time to work collaboratively with the instructor and their peers to share their understanding of the video lessons. After demonstrating their ability to analyze and evaluate specific elements of the video lessons, homework and assignments were conducted inside the classroom. After each lesson, students took a quiz to ensure understanding of the learning material. In the evaluation phase, students in both groups were post tested to measure the degree of change occurring as a result of the treatment. In addition, the experimental group was surveyed using the student perception questionnaire to examine the students' views of the flipped instruction. Figure 1 illustrates the study procedure for both groups (Appendix - Figure 1).

\subsection{Data Analysis}

The data collected from the two classes were organized into two separate parts: the results from the pretest and posttest scores and the responses from the computer use questionnaire and student perception questionnaire. The pretest and posttest were used to analyze student academic performance and contained the same items, but organized in a different random order. Answers were graded either correct or incorrect. One-way ANCOVA was used to examine whether there was a significant difference between groups on student academic performance.

The data from the questionnaire responses comprised of quantitative and qualitative items. The computer use questionnaire contained two closed-ended questions and three open-ended questions based on student ability and frequency of using computers and the internet. Finally, the student perception questionnaire consisted of 16Likert scale questions with 5-point response scale ranging from 1 (strongly disagree) to 5 (strongly agree) and two openended questions.

\section{Results}

\subsection{Results from the Computer Use Questionnaire}

Since this study was conducted in two advanced EAP writing courses via a blended format, a computer use questionnaire was distributed among students in both groups at the beginning of the semester in order to examine their ability and frequency of using computers and the internet. Responses from the computer use questionnaire provided a better overview of the participating students and their computer skills. Having access and the ability to use computers and the internet was especially important in this study to ensure that student academic performance and perceptions of the flipped model would not be compromised. The computer use questionnaire consisted of two closed-ended questions and three open-ended questions. Results from the closed-ended questions indicated that all students in both groups had access to a computer at home. Even though all students in the flipped group had access to the internet, 5 percent of students in the traditional group did not have access to the internet at home. Results from the open-ended questions showed that there was a small percentage difference between the control group and the experimental group. Regarding the hours spent using a computer or the internet in school or at home, students in the flipped group spent an average of 4.7 hours per day using a computer and an average of 5.9 hours per day using the internet in school or at home. When combining the hours spent on a computer and on the internet, students spent an average of 4 hours for school related work. On the other hand, students in the traditional group spent an average of 3.4 hours per day using a computer and an average of 2.8 hour per day using the internet in school or at home. In addition, they spent an average of 3 hours on a computer or on the internet doing school work. Figure 2 displays the average of hours each group used computers and the internet for school work (Appendix - Figure 2).

\subsection{Results for Student Academic Performance}

To address the first research question, analysis was carried out using SPSS 22 with the alpha level set at .05. Descriptive statistics were performed to summarize the means and standard deviations of the overall pretest and posttest scores for both groups. Table 1 illustrates descriptive statistics of both groups and summarizes the group comparison results for student academic performance at pretest and posttest (Appendix - Table 1). Before running the statistical analysis to compare groups at posttest, one-way ANOVA was performed to analyze the comparability between groups at pretest. Results indicated that the pretest scores did not differ significantly from the dependent variable (posttest scores), $F(1,20)=.035, p>.05$. That is to say that students in both groups started at the same point and any differences between the flipped group and the traditional group were attributed to the treatment. To address student academic performance, one-way analysis of covariance (ANCOVA) was performed to investigate whether the flipped classroom model positively impacted student academic performance using a pretest and a posttest as the primary measurement. 
Levene's test and normality checks were carried out and the assumptions met. The pretest was used as a covariate to control for initial group differences on student academic performance. Results from one-way ANCOVA showed statistically significant differences in mean scores between groups at posttest scores, $F(1,19)=5.534, p<$ .05. In other words, results indicated that students in the flipped group performed better than students in the traditional group. Table 2 displays the SPSS results of the ANCOVA with the pretest as covariate (Appendix Table 2).

\subsection{Results from the Student Perception Questionnaire}

The second research question explored students' perceptions of the flipped instruction using the student perception questionnaire. The questionnaire was twofold: the quantitative portion which contained 16closedended questions on a 5-point Likert scale, ranging from 1 (strongly disagree) to 5 (strongly agree), and the qualitative portion which included two open-ended questions.

\subsubsection{Quantitative Results}

Results from the quantitative portion of the questionnaire strongly indicated that students perceived the flipped classroom model as a positive experience. All students (strongly) agreed that they liked being taught using the flipped classroom model. Ninety-two percent of students (strongly) agreed that they learned better in the flipped model rather than in the traditional classroom instruction. Only 8 percent neither agreed nor disagreed with this statement. When asked whether the flipped model made it easier to understand the course content and whether the in-class work helped them to learn the course content, all students (strongly) agreed that the flipped classroom model made it easier to understand the course content and 92 percent (strongly) agreed that in-class work helped them. Only 8 percent disagreed with the latter statement. When the students were asked whether they preferred to watch a traditional teacher led lesson rather than a video lesson, there was a mix of responses. Twennty-three percent of students indicated that they strongly agreed to watch teacher led lessons, 8 percent agreed, 23 percent neither agreed nor disagreed, 38 percent disagreed, and 8 percent strongly disagreed. All students (strongly) agreed that they liked watching the lessons on video and that the lesson videos were easy to understand and helped them deeply understand the topic learned. Additionally, 92 percent of students (strongly) agreed that they were active listeners when they watched the videos. Only 8 percent neither agreed nor disagreed. When asked about class time, all students (strongly) agreed that the flipped classroom gave them more valuable time in class to practice and work on problems with their peers. Regarding their opportunity to communicate in class, 92 percent of students (strongly) agreed that the flipped model gave them greater opportunities to communicate with other students and the teacher. Eight percent strongly disagreed with the latter statement. Furthermore, 84 percent (strongly) agreed that the flipped classroom was helpful to do course exercises because other students and the teacher were available to answer questions as opposed to doing the homework exercises by themselves at home. Eight percent disagreed with the latter statement, and 8 percent neither agreed nor disagreed. Additionally, all students (strongly) agreed that the flipped classroom was more enjoyable, motivating, and engaging than the traditional classroom instruction. Finally, 92 percent of students (strongly) agreed that they improved their learning of grammar and writing, and that they would recommend the flipped instruction to a friend. Table 3 illustrates the results based on the quantitative results of "strongly agree" and "agree" from the 16 Likert-scale questions (Appendix - Table 3).

\subsubsection{Qualitative Findings}

Students were also given an opportunity to answer open-ended questions about the advantages and disadvantages of the flipped instruction. Each theme that emerged from the data is described, discussed and supported with examples. Responses to the advantages of the flipped instruction were extremely varied. The major categories that emerged were time, video content, and interaction. For the concept time, flexible scheduling and extra time given at home were concepts that students indicated that made a difference in improving their writing skills. Some of the comments focused on flexible scheduling as pacing and timing spent while watching the video lessons at home, as described below: Students can use lecture materials at their own pace, [and] students can review and replay any parts of the lecture that they are having problems with as many times as they need.

I have the opportunity to learn in my own rhythm.

Also, we can pause the videos as many times we want and have contact with the instructor to solve any question.

A flipped classroom lets me learn in my own time in my own place.

I can [watch] the videos as many times as I want. It helped me a lot. 
Student comments were also about the extra time given at home to learn more about the course content and how they came prepared to the next class meeting. Examples of student comments included:

The advantage of the flipped classroom is [that] we spend more time at home learning.

Flipped classroom [provides a] great opportunity for students to learn at home.

I learn more about the lessons because I have prepared myself at home.

I come to class with the material learned.

Besides, this method helped me to work and [be] prepared in advance with the rest of the class.

Furthermore, one concept that was relevant to the study was interaction. Three themes emerged: interaction with the instructor, interaction with the peers, and collaboration. Students mentioned the advantages of interacting and collaborating with the instructor and their peers in the flipped classroom, as stated below:

[There is an] interaction with the professor; we can resolve immediately any doubts about the course.

I can interact with my classmates, ask [about] the topic that is not well understood, and clarify my question marks with the teacher.

Also[there is]more time for collaborating with other classmates.

Video content was a minor concept identified during the questionnaire but relevant to the study. Students commented on the video content and how much they liked watching the videos, indicating that by understanding the video lessons, students were motivated and had the ability to comprehend the content, thus improve their writing knowledge of the lessons. Examples of student comments included:

I like the way the videos explain and the activities really help me to understand the content.

I like the video and understand the content so more videos should be implemented in all EAP classes in order to better understand course content.

Responses regarding the disadvantages of the flipped classroom tended to focus on issues with internet access, workload, and lack of homework. Regarding problems with internet connection, students commented that sometimes they did not have access to the internet and could not complete their school work. Examples of student comments included: The student should have access to the internet, but not all students have this access.

The disadvantage is when I don't have signals and can't log in due to malfunctions.

About workload, students mentioned that there was more work involved and more time consuming than traditional courses. Examples of student comments included:

[W] atching the whole list of videos on the Internet is not bad, but it takes time.

[Y]ou have to dedicate too much time at home and if you are a little bit busy you do not have enough time.

However, other student comments highlighted the lack of homework provided. Some desired more opportunity to do homework at home. Comments included:

To improve I recommend receiving more material for practice at home or allow students to create groups for debate about class topic.

[It is necessary] more exercises about [class] topic so students can improve their learning.

\section{Discussion}

This study investigated the impact of the flipped classroom model on student academic performance in blended learning environments. Additionally, students were provided a perception questionnaire to give them an opportunity to express their views on the flipped instruction. Before analyzing the data from the pretest and posttest scores and responses from the perception questionnaire, students were initially given a computer use questionnaire so their ability and frequency of using computers and the internet could be examined. By analyzing the responses from the questionnaire, it was determined that students' ability to use computers and the internet would not compromise their pretest and posttest scores and perceptions of the flipped instruction. Results showed that all students in both groups had access to computers and the internet, suggesting that students were similarly prepared to use computers and the internet in this study. Similarly, students in both groups spent a similar number of hours using computers or the internet to complete school work at home or in school. To address the first research question, statistical analysis showed that students performed better by completing their lecture via video lessons at home and homework and assignments during class meetings. Therefore, results regarding student academic performance suggested that the flipped instruction facilitated student learning compared to the traditional lecture instruction in blended EAP learning contexts. The second research question sought to understand student perceptions of the flipped instruction. 
Results of the qualitative analysis supported the quantitative findings, providing additional insight into the student perceptions of the flipped classroom model. In short, students expressed a preference for the flipped instruction over the traditional lecture teaching. Open-ended comments from the student perception questionnaire provided supporting evidence that the flipped model is a great approach to teaching that positively impacts student academic learning outcomes. Students responding positively to the flipped classroom model are important because it can impact their motivation and, therefore, student success. This is confirmed in the students' responses in which they revealed that they were more engaged, motivated, and active in learning due to the flipped instruction. In addition, the flipped model is argued to be a helpful tool for at-risk students (Hughes, 2007; Peterson, 2016). It is hypothesized "that the flipped structure benefits weaker students more because of increased face time with the instructor, increased collaboration with stronger peers, and more flexibility to slow the pace of their learning outside class" (Peterson, 2016, p. 14). However, there has yet to be any exploration of this question and no data to support this hypothesis, especially within the flipped model in the field of English for Academic Purposes.

It is also important to point out the limitations of this study. Because it is impossible to randomize enrolled subjects in educational settings, this study was not a true experiment since participants were not randomly assigned to conditions. Additionally, this quasi-experimental study used limited sample size, so findings were not meant to be generalized. Thus, further research would be needed to fully consider how the flipped model could be applied to larger groups in order to observe whether or not achievement trends would continue. Furthermore, the flipped model would need to be tested with a large sample size with different groups, subjects, and assessment types. Due to the lack of empirical studies in flipped classroom in EAP courses, this study and its findings may shed some light for practitioners considering implementing the flipped model in their own professional practices.

\section{Conclusion}

Students enrolled in writing classes need to be allocated more class time to work on their writing assignments, receive constructive feedback from their instructor and peers, and reflect on their own work. Providing students with interactive activities and collaboration during class time can enhance student academic performance. Positive results from this study demonstrated that the application of the flipped classroom model can enhance student academic performance. Students learn and construct their own knowledge through group interaction and guidance from the teacher in in-class activities. Furthermore, students perceive the learning experiences positively as they engage in the learning process. The flipped classroom is considered to be an innovative teaching approach to learning. By flipping the class, students are introduced to course content via video lessons prior to class in order to dedicate class time to exploring topics in greater depth. Additionally, the flipped model fits well with the increasing use of educational technology and adaptive learning in the classroom. Thus, integrating technology and a prominent teaching approach into the educational process can positively affect student learning. 


\section{Tables and Figures}

\section{Appendix}

Control Group

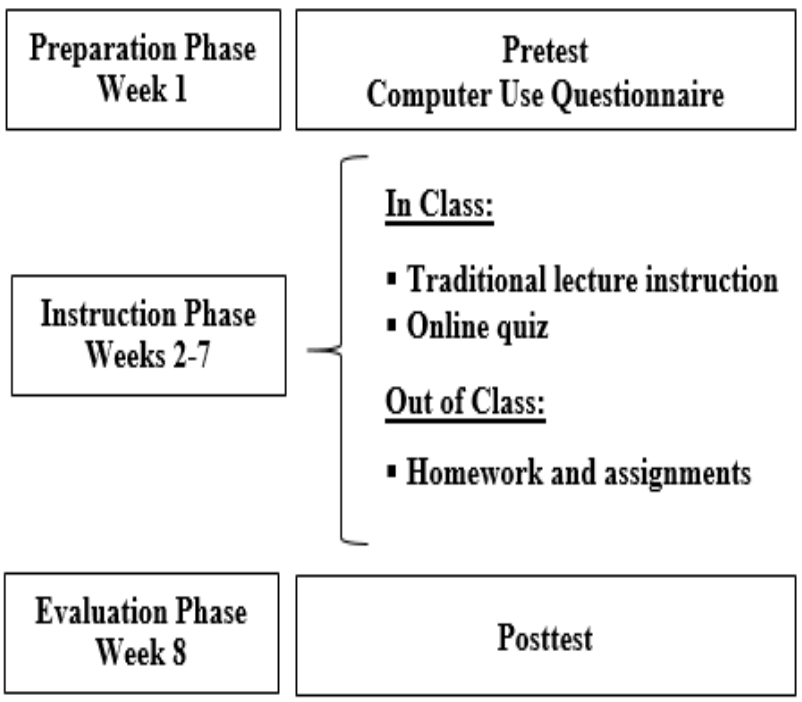

Experimental Group

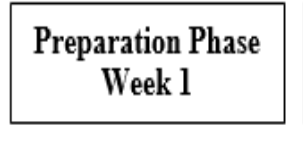

\begin{tabular}{c} 
Pretest \\
Computer Use Questionnaire \\
\hline
\end{tabular}

Out of Class:

- Flipped instruction via online video lessons

In Class:

- Homework and assignments

- Online quiz

Evaluation Phase
Week 12

\begin{tabular}{|c|}
\hline Posttest \\
Student Perception Questionnaire \\
\hline
\end{tabular}

Figure 1.Study Procedure for Both Groups

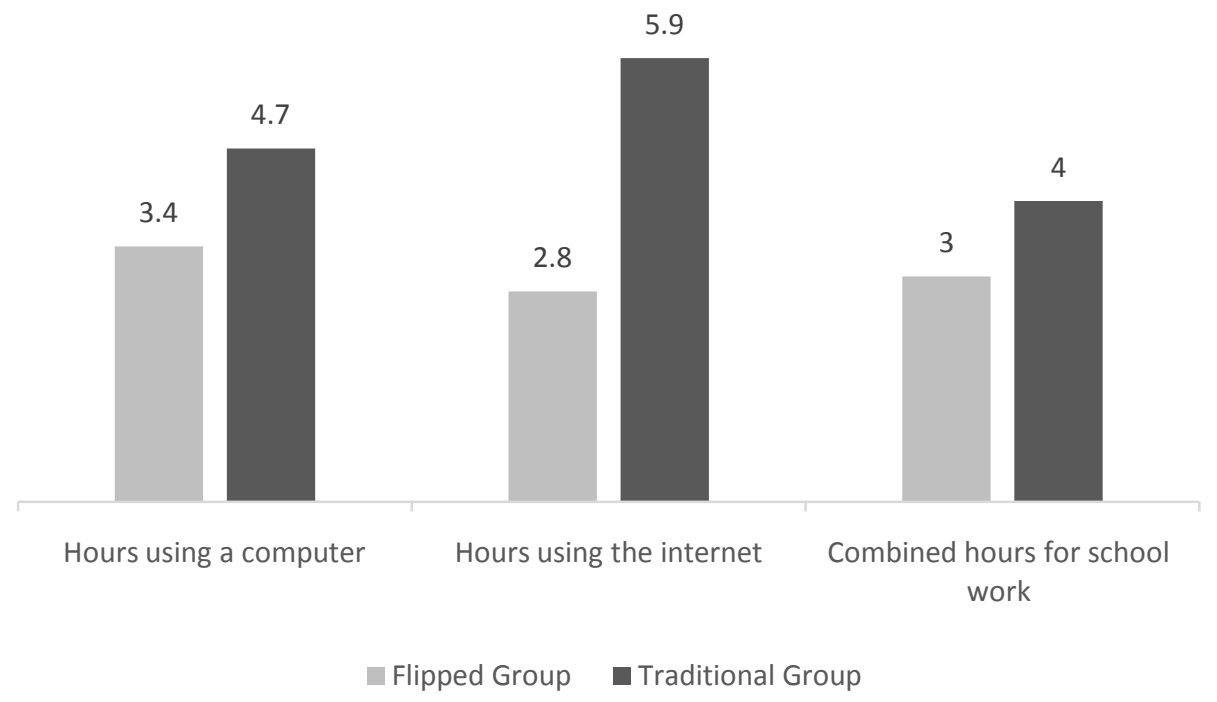

Figure 2. Average of Hours Using a Computer and the Internet for School Work 
Table 1

Means and Standard Deviations for Pretest and Posttest Scores

\begin{tabular}{lllll}
\hline & Pretest & \multicolumn{3}{l}{ Posttest } \\
\cline { 2 - 5 } Group & $M$ & $S D$ & $M$ & $S D$ \\
Traditional $(n=9)$ & 26.44 & 5.08 & 31.44 & 5.90 \\
Flipped $(n=13)$ & 26.85 & 4.81 & 36.15 & 5.41 \\
\hline
\end{tabular}

Table 2

ANCOVA Results Comparing Posttest Scores by Groups with Pretest as Covariate

\begin{tabular}{llllll}
\hline Source & $S S$ & $d f$ & $M S$ & $F$ & $p$ \\
\hline Pretest & 276.107 & 1 & 276.107 & 14.827 & .001 \\
Posttest & 103.057 & 1 & 103.057 & 5.534 & .030 \\
Error & 353.808 & 19 & 18.621 & & \\
Total & 26521.000 & 22 & & & \\
\hline
\end{tabular}

Note* ${ }^{*}<.05$

Table 3

Quantitative Results from the Student Perception Questionnaire

\begin{tabular}{|c|c|c|c|}
\hline & Questions & $\begin{array}{l}\text { Strongly } \\
\text { Agree }\end{array}$ & Agree \\
\hline 1 & I like the Flipped Classroom & $92 \%$ & $8 \%$ \\
\hline 2 & $\begin{array}{l}\text { I learn better in the Flipped Classroom rather than in } \\
\text { traditional classroom instruction }\end{array}$ & $62 \%$ & $30 \%$ \\
\hline 3 & $\begin{array}{l}\text { The Flipped Classroom makes it easier to understand the } \\
\text { course content }\end{array}$ & $70 \%$ & $30 \%$ \\
\hline 4 & $\begin{array}{l}\text { I would rather watch a traditional teacher led lesson than a } \\
\text { lesson video }\end{array}$ & $23 \%$ & $8 \%$ \\
\hline 5 & I like watching the lessons on video & $92 \%$ & $8 \%$ \\
\hline 6 & The lesson videos are easy to understand & $70 \%$ & $30 \%$ \\
\hline 7 & The lesson videos help me deep understand the topic learned & $77 \%$ & $23 \%$ \\
\hline 8 & I am an active listener when I watch the videos & $62 \%$ & $30 \%$ \\
\hline 9 & $\begin{array}{l}\text { The Flipped Classroom gives me more valuable time in } \\
\text { class to practice and work on problems with my peers when } \\
\text { I watch the lesson videos at home }\end{array}$ & $77 \%$ & $23 \%$ \\
\hline 10 & $\begin{array}{l}\text { The Flipped Classroom gives me greater opportunities to } \\
\text { communicate with other students and the teacher }\end{array}$ & $77 \%$ & $15 \%$ \\
\hline 11 & $\begin{array}{l}\text { It is helpful to do course exercises when other students and } \\
\text { the professor are available to answer questions as opposed } \\
\text { to doing the homework exercises by myself }\end{array}$ & $46 \%$ & $38 \%$ \\
\hline 12 & The Flipped Classroom is an enjoyable way to be taught & $85 \%$ & $15 \%$ \\
\hline 13 & $\begin{array}{l}\text { The Flipped Classroom is more engaging than traditional } \\
\text { classroom instruction }\end{array}$ & $77 \%$ & $23 \%$ \\
\hline 14 & I am more motivated to learn in the Flipped Classroom & $77 \%$ & $23 \%$ \\
\hline 15 & I feel I have improved my learning of grammar and writing & $77 \%$ & $15 \%$ \\
\hline 16 & I would not recommend the Flipped Classroom to a friend & $8 \%$ & $0 \%$ \\
\hline
\end{tabular}




\section{References}

Bergmann, J., \&Sams, A. (2012). Flip your classroom: Reach every student in every class every day. International Society for Technology in Education, Washington, DC.

Bishop, J. L., \&Verleger, M. A. (2013, June). The flipped classroom: A survey of the research. In ASEE National Conference Proceedings, Atlanta. GA.

Brame, C. J. (2013). Flipping the classroom.Center for Teaching, Vanderbilt University. Retrieved from: http://cft.vanderbilt.edu/guidessub-pages/flipping-the-classroom/

Butt, A. (2014). Student views on the use of a flipped classroom approach: Evidence from Australia. Business Education \& Accreditation, 6(1), 33-110.

Creswell, J. W., \& Plano Clark, V. L. (2011). Designing and conducting mixed methods research. Thousand Oaks, CA: Sage.

DiRienzo, C., \& Lilly, G. (2014). Online versus face-to-face: Does delivery method matter for undergraduate business school learning? Business Education \& Accreditation, 6(1), 1-11.

Hamdan, N., McKnight, P., McKnight, K., \&Arfstrom, K. M. (2013). The flipped learning model: A white paper based on the literature review titled a review of flipped learning. Flipped Learning Network: Pearson.

Hughes, G. (2007). Using blended learning to increase learner support and improve retention. Teaching in Higher Education, 12(3), 349-363.

Hung, H. T. (2015). Flipping the classroom for English language learners to foster active learning. Computer Assisted Language Learning, 28(1), 81-96.

Johnson, R. B., \&Onwuegbuzie, A. J. (2004). Mixed methods research: A research paradigm whose time has come. Educational Researcher, 33(7), 14-26.

Johnson, R. B., Onwuegbuzie, A. J. \& Turner L. A. (2007). Toward a definition of mixed methods research. Journal of Mixed Methods Research, 1(2), 112-133.

Little, C. (2015). The flipped classroom in further education: Literature review and case study. Research in PostCompulsory Education, 20(3), 265-279.

Peterson, D. (2016). The flipped classroom improves student achievement and course satisfaction in a statistics course: A quasi-experimental study. Teaching of Psychology, 43(1), 10-15

Strayer, J. (2012). How learning in an inverted classroom influences cooperation, innovation and task orientation. Learning Environments Research, 15(2), 171-193.

Thompson, S., \&Mombourquette, P. (2014). Evaluation of a flipped classroom in an undergraduate business course.Business Education \& Accreditation, 6(1), 63-71.

Tucker, B. (2012). The flipped classroom. Education next, 12(1).

Westermann, E. B. (2014). A half-flipped classroom or an alternative approach?: Primary sources and blended learning. Educational research quarterly, 38(2), 43-57. 